\title{
Davor Bolf
}

E-mail: dbolf@riteh.hr

\author{
Albert Zamarin \\ E-mail: zamarin@riteh.hr \\ Robert Basan \\ E-mail: robert.basan@riteh.hr \\ University of Rijeka, Faculty of Engineering \\ Vukovarska 58, 51000 Rijeka, Croatia
}

\section{Composite Material Damage Processes}

\begin{abstract}
Composite materials are in use in the shipbuilding industry for a long period of time. Composites appear in vast number of fibre - matrix combinations and can be produced with several different production processes. Due to the specific nature of the composite material structure, the selection of the production process and the limitations in the quality control procedures, composite materials will always be subject to defects and imperfections which may, under certain circumstances, lead to the appearance and propagation of cracks. The size and the shape of the crack, the load type and the stress field in the material surrounding the crack will be crucial for crack growth and crack propagation. This paper reviews the composite material damage processes especially relevant for shipbuilding. The basic principles of composite material fracture mechanics are briefly explained, and finally, mechanisms responsible for the development of damage and fracture of composite materials are presented. This paper has emerged from the need to summarize information about composite material fracture and failure mechanisms and modes relevant for the shipbuilding industry.
\end{abstract}

Keywords: composite material damage, composite material fracture, fracture mechanics, composites

\section{Introduction}

Composites or composite materials in shipbuilding industry appear in various combinations of resin (matrix) and reinforcements (fibres). In addition to the matrix and fibre reinforcements, core materials can also be used to form a structural solution called sandwich laminate. Above mentioned materials such as matrix, fibres and cores form single skin or sandwich laminates which are most commonly encountered in smaller ships and boats and as such are already considered as classic structural solutions 
in shipbuilding. Composite materials are often used as building material for main structural elements in yachts and boats up to 20 meters, while in larger ships the use is restricted to parts of the ship's structure, i.e. superstructures, radar and sonar domes, as well as various other structural and non-structural elements.

Composite material structure is fundamentally different from homogeneous steel structure. Likewise, the design criteria of the composite structures differ from the criteria applied to the steel. The use of composites in ship structure requires a deeper insight and understanding of the mechanics of the composites materials as well as the features of composite material production processes. No matter how precise the production process is, there will always be imperfections and defects in the produced composite material. The size and the type of imperfection, as well as the type and direction of load will be decisive factors whether the material will withstand the load or whether the crack will initiate and propagate through the material. A large number of microscopic imperfections can abruptly escalate into a macroscopic failure leading to significant structural damage.

Damage processes and material behaviour during the failure of the material and structure will be listed in the text below. Cases taken into account are the most relevant forms of material damage processes and failure mechanisms in shipbuilding practice and vessel exploitation.

\section{Composite material damage processes}

Different composite material design solutions, load cases and environmental conditions will influence the process under which the damage will occur. Damage mechanisms pertinent to composite materials are quite complex. Observing only the stiffness criteria and/or the strength criteria will not give all the answers to the question of how long the composite material will withstand the load, or predict its life span. All of the below mentioned processes can occur during the exploitation or production of the vessel.

\subsection{Fatigue}

Ship or almost any other marine object is in its exploitation life subjected to various dynamic loads such as wave loads, vibrations, sloshing, slamming etc. Subjected to these repeating loads material loses required stiffness or loses required strength. Material fatigue usually starts in the initial crack or imperfections of the material, which after a number of cycles begins to expand and propagate. Unlike metallic materials, there are four basic mechanisms of composite material failure as a result of fatigue: matrix cracking, delamination, fibre breakage, and interfacial debonding [1].

According to [1], throughout its lifetime, composite material subjected to fatigue loads goes through five phases: 
- breakage of the matrix and / or fibres

- crevice cracking, matrix fibre peeling, fibre breakage

- delamination, fibre breakage

- crack growth through delamination, fibre breakage

- breakage of material

There are many theories that attempt to explain and describe the impact of material fatigue on composites. However, currently there is no reliable method to describe the behaviour of the composite in all cases and composite material combinations and layouts. Weibull distribution and variations of the formula is often used as the most accurate prediction method for damaging behaviour and longitudinal tensile failure of a unidirectional fibre lamina [2]. Also modifications on static strength theory have been attempted and some of extended formulas have been in use to predict the composite behaviour under cyclic loading. The need arose to calibrate formulas and back them up with test data in [3] and [4]. However, this can only be used on specific cases and in order to estimate results as there are too many variables to accurately describe the material behaviour using such simplified approach. Therefore, new methods have been proposed and tested for various fibre - matrix combinations, using similar fibres [5], [6] and also dissimilar combinations of fibres [7], as well as sandwich structures [8]. New methods have also been introduced using the extended finite element modelling method [9] and computer aided design and programing [10] trying to predict behaviour of the mixed composite on representative volume element level as well as to calibrate software inputs.

\subsection{Impact (collision)}

When designing a vessel, impact is rarely the one of the cases that designers take as relevant state of loading condition. In case the vessel is intended for operations during which it is frequently in contact with the shore, other vessels, etc., impact needs to be taken into account. When designing tugs, work boats impact can also be referred as a collision. Similarly, the designers of the sailing yachts and boats, when designing the keel and surrounding structure need to take into account the grounding and collision load cases, see Figure 1. Some of the warships, especially minesweepers and similar purpose vessels are also designed to withstand underwater blasts [11]. However, data from these calculations and tests are often hard to find and not readily available.

An impact can be divided into several cases. If the structure is sufficiently stiff, the entire collision energy is absorbed into the elastic deformation of the structure. After impact the structure returns to its initial position. If the structure is not stiff enough to absorb all of the impact energy, some of the energy is absorbed in the form of plastic deformation of the structure. Finally, if the collision energy greatly exceeds the strength of the material, the structure itself will break. Cracking of fibres, matrix or delamination can occur in these cases. Impact with smaller objects was particular interest of research in aerospace applications [12], but can find its uses in shipbuilding as well. 
In general, the behaviour of a composite during a collision can be described in several stages:

- collision and energy absorption

- elastic deformation

- matrix breakage

- delamination

- fibre breakage

- peeling and / or breaking the core of the sandwich laminate [1].

Recently, experiments were conducted in order to gain more accurate experimental data and find analytical data to calibrate the numerical models, on smaller scales [14] as well as a real life cases [15].

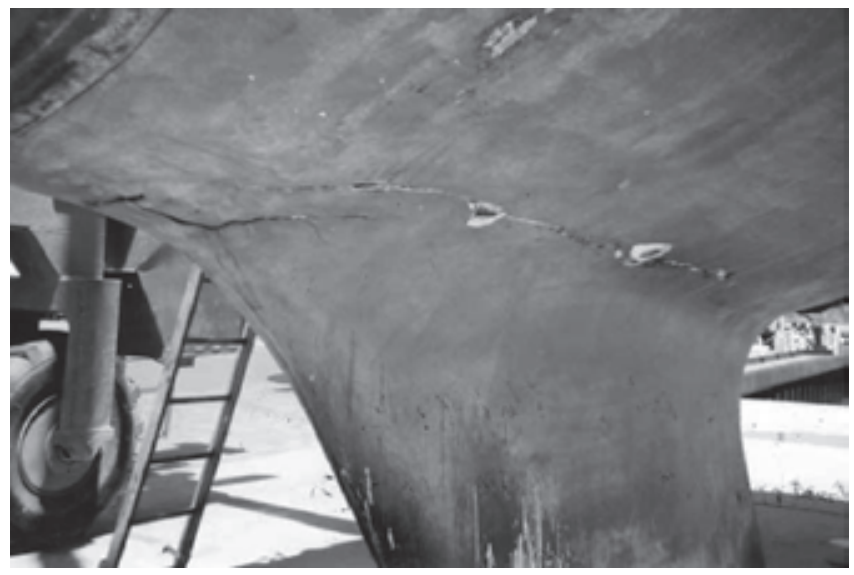

Figure 1: A large crack as a result of hard grounding [13]

\subsection{Delamination}

Delamination usually occurs in areas where the properties of one material are significantly different from those of surrounding material. The existence of the interlaminar stress, the cause of the delamination process, indicates that laminate can fail around the edges or holes and such failure cannot be neglected when designing with the composite material. Some of the most common cases and positions where delamination can occur are illustrated on Figure 2. 

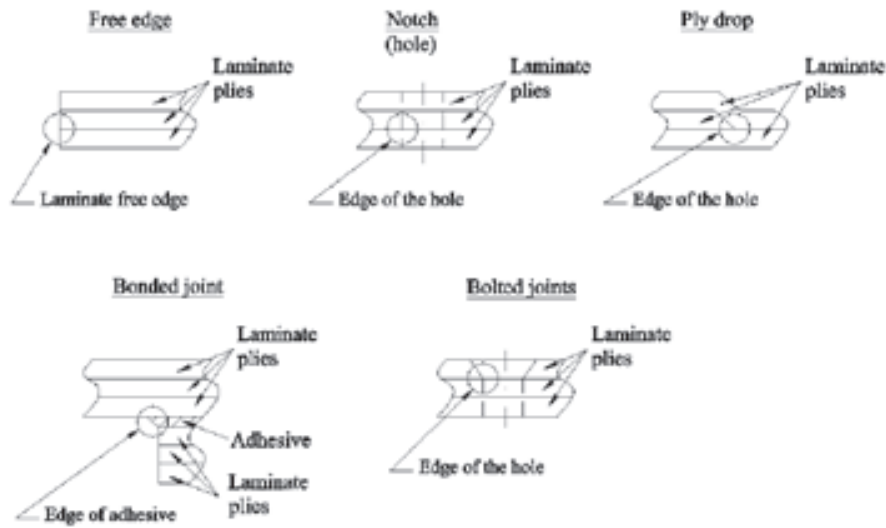

Figure 2: Sources of out-of-plane loads from load path discontinuities

Delamination manifests itself as the crack propagating between layers of composite material. Interlaminar stress is difficult to determine using just classical laminate theory [16]. As presented in classical laminate theory, the joint between the layers is considered perfect and its thickness is 0 . Therefore, there are no shear stresses at the edges of the laminate $\left(\tau_{z x}\right.$ and $\left.\tau_{z y}\right)$, nor normal stress in the z-axis $\left(\sigma_{z}\right)$. Thus, classical laminate theory cannot fully explain the mechanisms of delamination at the free edge of the laminate, one of the most common causes of the laminate breaking. [17]. Therefore, an elasticity approach was suggested, using the three-dimensional stress state [18], thus forming the system of second order partial different equations through the section of the laminate. Proposed system was solved using the finite difference method and results were confirmed experimentally using the moiré technique [19]. The study intensified during eighties and nineties with usage of finite element method examining the notches in laminate [20] as well as the free edges of the laminate [21], [22] and [23], while also investigating more efficient ways of analytical calculations [24]. Some of the newer studies introduce the use of commercial software in modelling the interlaminar stress [25] and even the use of cohesive elements in finite element analysis [26].

\subsection{Blistering and water absorption}

Blisters usually appear in area of the laminate where excess fluid accumulates. Blisters are very easy to spot if they appear in gelcoat, the first layer of laminate, but in case they are formed inside the laminate itself, it is almost impossible to detect them without using some non-destructive material testing method (i.e. ultrasound). When the blister is punctured, the viscous fluid will usually flow from the blister. Depending on the cause of the blistering, the types of fluid in the blister may also differ. So the blister may contain a catalyst, water, solvent, oil and non-cured resin. 
There are usually two main reasons for blistering. The first is any imperfection created during the production of laminate. The second reason is osmosis and the environmental exposure of the laminate, in which case the water is most common type of fluid found in the blisters.

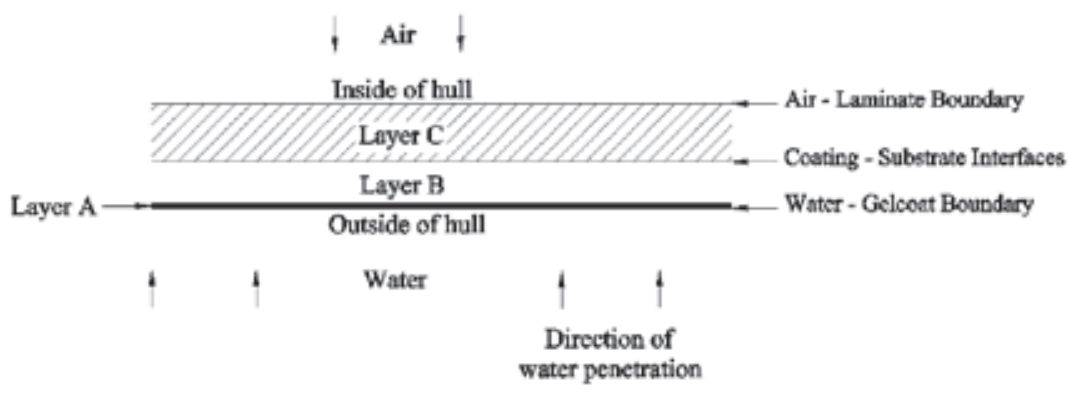

Figure 3: Structure description for the skin coated composites with: Layer $A=$ Gelcoat, Layer B = Interlayer, Layer C = Laminate Substrate according to [1]

Exposure of the laminate to the aquatic environment inevitably results in the transfer of water from the environment into the laminate itself, schematically shown on Figure 3. The transfer of water to the laminate is enhanced by temperature, and the transfer is influenced by the composition of the water. Thus, in warm, freshwater lakes the transition will be greater than in the North Atlantic, for example.

The transfer of moisture from the surrounding area to the laminate takes place over long periods of time. Filled with water, laminate begins to lose its properties over time and weakens. According to some experimental data reported in the literature [1], the laminate strength can be reduced to up to $40 \%$ of the initial strength.

Water absorption takes place exclusively in the matrix (especially within composites using polyester and vinyl ester resins). Experimental data has also shown more degradation in physical properties of orthophthalic resins over the isophthalic resins [27]. Through several experiments, the voids in the laminate were pinpointed as places suitable for detaining the water. Therefore, the voids were observed [28] to study the influence of water absorption on laminate properties, as well as the influence of production processes [29] on number of imperfections suitable for water absorption. Laminates with more imperfections were prone to absorb more water.

Prevention of blistering caused by production process can be easily achieved with more rigorous quality control. Blisters caused by water absorption can also be prevented by selecting the proper matrix material and coating, as shown in [30] and [31]. For that purpose, new coatings are investigated [32]. There are also patented procedures for drying moisture from laminates [33], but their efficiency needs to be experimentally checked and approved. 


\subsection{Cracks in gelcoat}

Gelcoat is often not considered as an integral part of the laminate and often it is not included in the calculation of the strength of the laminate. Although it consists mainly of a matrix, as the most exposed laminate layer, in some cases it can be significantly subjected to external loads and it is not advisable to neglect cracks and damage that might appear in gelcoat. The thickness of the gelcoat layer has significant role in surface appearance and also the performance of the laminate [34]. Its performance can be enhanced by adding the nanoparticles [35] or other additives and structural strength of the gelcoat can be increased. As the first layer of the laminate, gelcoat protects the laminate from environmental influences.

Damage in gelcoat can easily be visually inspected. Depending on its visual appearance, crack damage can be divided into three basic types. This is illustrated on Figure 4, where three distinctive type of damage are shown. Type I is most often caused by changes in the thickness of the gelcoat layer, causing the cracks to spread radially from the area that is most loaded. It can occur at the part where the protective decorative layer is thickest, but also at its thinnest part. If the focal point of the radial spread is in the centre of the panel, a cause of the cracks can be excessive deformation of that panel. Type II commonly occurs on structure and hull area, the most common cause being thermal stretching of the structure and/or fatigue of the material. The cracks in the gelcoat layer in this case are arranged parallel to the fibres. They are extremely dangerous because they can propagate into adjacent layers of laminate, ultimately causing the failure of the laminate. Type III is self-evident and occurs around the opening. Usually it is the result of poor design of the surrounding reinforcement around the opening, a stress concentration occurs around the hole and cracks expand around the hole. 


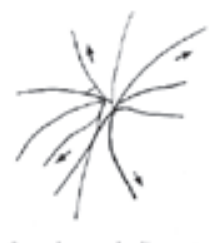

Seccedary cacbs Liverge os less desiity

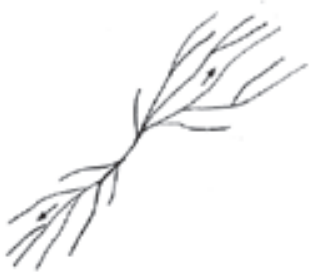

Type I - Radial or Divergent Configuration

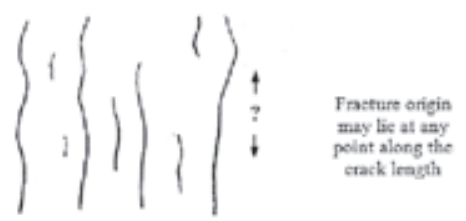

Type II - Randomly Spaced Parallel and Vertical Fractures

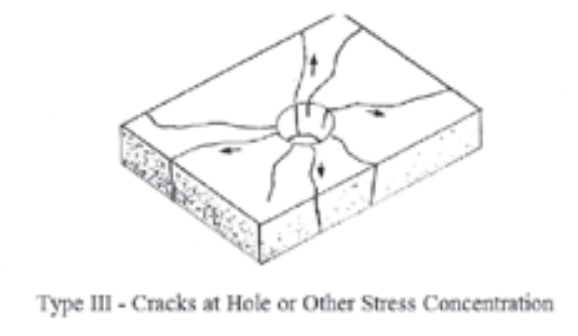

Type III - Cracks at Hole or Other Stress Concentration
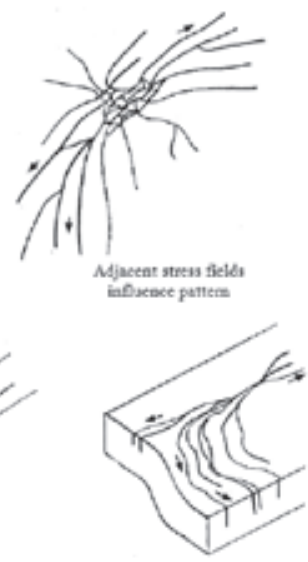

it along the

eck leagth .

Figure 4: Schematic representation of gelcoat crack patterns [1]

\subsection{Sandwich delamination}

Sandwich laminate is extremely popular in boatbuilding. It increases the thickness of the laminate while minimally increasing the weight of the boat. Using the sandwich in composite structures, panel gains rigidity and higher strength. One of the common damage processes that occurs in sandwich plates is the separation of the core of the sandwich panel from the laminate skins.

The reasons for this may be different, from imperfections created due to the 
production process to the failure in design. The most common causes are insufficient core preparation, surface impurities, or premature application of the next layer of laminate. Sandwich panel, subjected to a certain load case (namely compression or flexion) due to the factors mentioned before, often experience delamination of the skins. Therefore, sandwich delamination is often one of the observed processes during the testing of the sandwich panel behaviour, as in [36].

A novel solution of composite shear keys is presented in order to minimize the influence of imperfections created in the production process and trying to raise the safety and stability of sandwich structures. The shear keys can be inserted into the core of sandwich laminate to prevent the delamination of the skins due to the shear loads, as explained in [37], [38] and [39].

\subsection{Ultraviolet light degradation}

Polyester, vinyl ester, and epoxy resins are degraded when exposed to Ultraviolet light (UV) over extended period of time. In order to protect and prolong the life of the laminate, the vessels are coated with a protective layer that contains fillers. Resins that are least sensitive to UV degradation are polyester orthophthalic and isophthalic resins. Therefore, the protective decorative layer is basically a polyester resin with the addition of fillers and UV inhibitors [40].

However, even such resins, due to prolonged exposure to UV light, often became damaged and cracked. The colours of the protective coating change due to exposure (e.g. the white coloured layer becomes yellowish). After a time of exposure to UV radiation, the glossy surface of the layer becomes completely damaged, leaving a rough chalky surface. Damaged layer will eventually fail and degrade in such manner that cracks will propagate to surrounding laminate. Protecting the composite laminate with appropriate protection, composite material will at the end have better mechanical properties and longer life span than unprotected composite [41].

\section{Basic principles of composite material fracture mechanics}

Development and propagation of the crack is one of the most common mechanisms of damage to isotropic, brittle materials [1]. Due to variations in laminate composition, the use of matrices and fibres of dissimilar properties, it is difficult to determine the unique and unambiguous crack propagation in the composite material.

Damage, i.e. cracking of the composite material can be viewed from the aspect of satisfying the rigidity criteria or meeting the strength criteria. In the case of strength criteria, fracture occurs when the stress in the laminate reaches values greater than the values that the laminate is capable of carrying. In the case of stiffness criteria, material deformation is of outmost importance. The laminate will crack if the material deforms more than it is allowed by the material properties. 


\subsection{Composite material fracture}

If the composite material is considered as a homogeneous anisotropic material, all the main properties of fracture mechanics can be applied. The fracture mechanics of composite materials are known from Wu's work [42], which in addition to stress intensity factors considered other relevant factors, including material anisotropy and crack location. Observing the propagation of the crack in the composite material, he concluded that in case of the opening mode (mode I), the crack will propagate in the direction of fibres. Tests have shown that the propagation of a crack, regardless of the direction of loading or the angle of fibres, most often goes through the matrix. Even if initially formed perpendicular to the fibre direction, the crack will in most cases continue to propagate through the matrix as depicted on Figure 5.

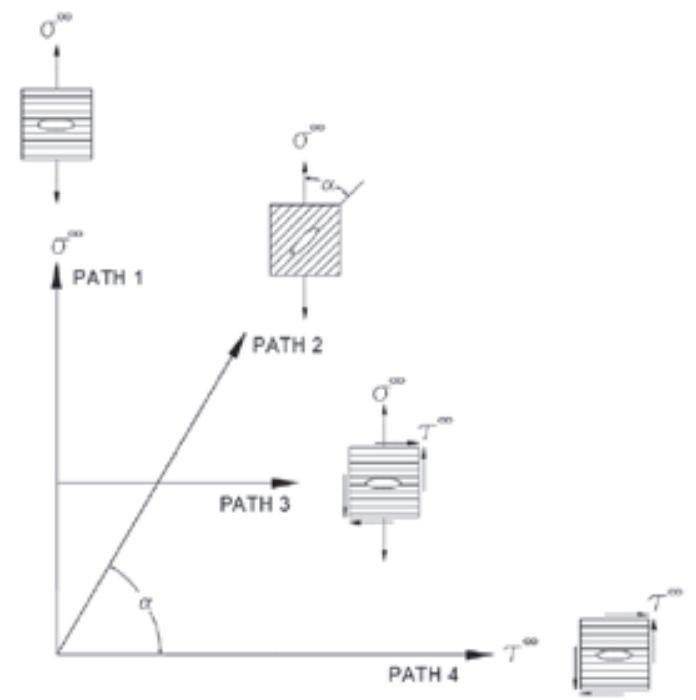

Figure 5: Direction of loading and cracking according to [17]

However, composite laminate is usually composed of several layers with different orientations, causing the crack to be self-similar in one layer, but not in the next one, not considering the delamination between the layers [43]. Therefore, as suggested in [44], the only exact method to estimate the crack growth in such composites is to test them according to the loads they will carry. Even though finite element method is not new to solving fracture mechanic problems as already seen in [45], new methods like extended finite element method with minimal remeshing [9] are also being developed and applied in the field of composite material fracture studies [46]. 


\section{Failure modes}

The classical engineering approach to structural design, is to take into account allowable stresses and design structure accordingly. However, considering the fact that during the manufacturing process there will always be imperfections in the material itself, it is necessary to include them in the calculation and to take into account the probability that under the influence of external forces, the defect in the material can increase enough to grow into a crack.

Having its structure in mind, there are two distinctive failures that can occur in composite material: failure of the matrix or failure of the fibres. Of course, there are cases where damage occurs both in the matrix and in the fibres itself. Some of the causes due to failures can appear are: fracture under the influence of tensile loads, fracture under the influence of compressive loads, buckling, bending, first ply failure, creep.

\subsection{Tensile failure}

Under the influence of tensile forces, the fibres can break. Broken fibre ceases to carry a load which is in that case transmitted to the surrounding fibres. However, as the fibre is immersed in the matrix, after a certain distance along the fibre length, the broken fibre will again start to carry load. Thus, the matrix transfers the load to the part of the fibre that is ready to take the load. The fracture of composite materials under the influence of tensile forces can be depicted in several steps. At first, threadlike cracks appear on the surface of the composite, then larger cracks become visible, and just before the fracture, the matrix becomes blurred and the material can be white coloured. When remaining fibres are not able to withstand the applied load, the composite material will break [47].

The tensile strength of the composite material can be represented by the stressstrain curve which may be more or less different from the curve representing the isotropic material curve. For the most of the composite materials this curve is similar to the curve of a brittle isotropic material. According to the literature [48], using the Weibull distribution function and the tensile strength of a composite, it is possible to predict to some extent the behaviour of the composite material in the damaged state. It is possible to determine the ratio of broken fibres to the total number of fibres in a given cross section using the formula 1 :

$$
D_{t 1}=F\left(\sigma_{1}\right)=1-e^{-\frac{1}{m e}\left(\frac{\dot{\sigma_{1}}}{F_{t 1}}\right)^{m},}
$$

where $D_{t l}$ is ratio of discontinuous fibres to total fibres, $m$ is Weibull shape factor, $\tilde{\sigma}_{l}$ is effective strain in the fibre direction, $F_{t l}$ is tensile strength of composite and $e$ is Euler number [2]. 
However, tensile loads can be applied along the fibre direction and also transversal to the direction of the fibres. To fully understand the mechanism, the test like in [49] and [50] still needs to be performed in order to clarify and describe the failure mechanics according to initial conditions and materials, although on micro level the prediction of the failure can be modelled using the numerical and finite element methods described in [51] and [52].

\subsection{Compressive failure}

Due to the impact of compressive loads, the laminate part will tend to buckle and kink. For the laminates made only of fibre and matrix, the buckling mechanism can be described in several steps.

The twisting in such laminates will occur due to the misalignment of the compressive force angle and the fibre direction. Fibres that are not completely parallel to the tensile force tend to bend. The more such fibres bend, the more adjacent fibres are loaded and tend to follow the buckling curve depicted in Figure 6. Good overview of compressive failure in long fibre polymeric composites was given in [53].

Sandwich panel buckling can take many forms and bending mechanisms contain many more variables. Some of the most common failures in the boatbuilding are described in [54], [55] and [56].

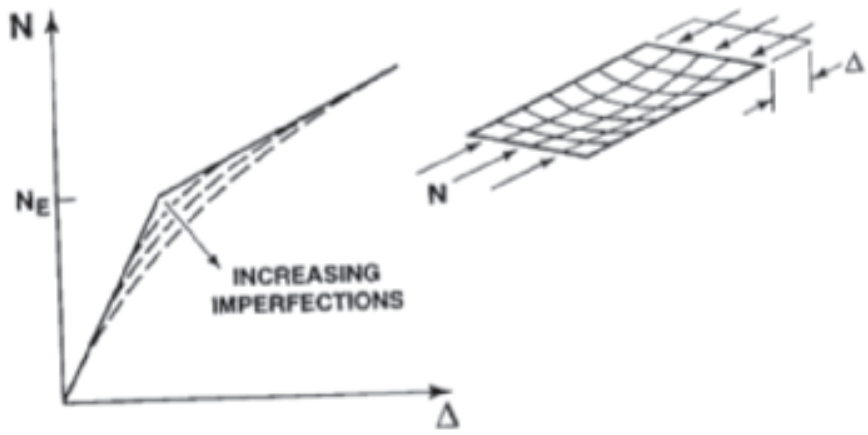

Figure 6: Buckling of the panel shortens the panel and increases the number of laminate imperfections [17]

\subsection{First ply failure}

First ply failure refers to the stress at which the ply of laminate will break and fail. In order to calculate the stress in the layer, it is necessary to determine the stress in all plies of the laminate and then check it against the ply material properties. Maximum stress is usually in the first or last layer of the laminate (farthest from the neutral axis), 
but the failure can occur in any ply which is not sufficiently strong enough to withstand the applied load. As the laminate is mostly made of layers of fibres arranged in different directions, failure of the first layer does not necessarily mean that all other layers will fail. The crack in the first layer spread through the matrix, affecting the fibres in the adjacent layer. As the fibres are in a direction different from the fibres in the first layer, they assume some of the stress. This is not the case for a unidirectional laminate where all layers are stacked in the same direction. The crack propagation of such laminate very likely encompasses all layers of the laminate.

First ply failure problems can be sorted in composite macro mechanics finite element analysis [57], but it can also be studied on the micromechanical level if the laminate is constituted exclusively of unidirectional laminate [58].

\subsection{Sandwich panel bending}

There are two cases of bending a sandwich panel. One is where the sandwich panel contains a core that is relatively rigid and can carry bending loads, and the case where the core is soft, and a large part of the shear stress is transmitted by the fibres in the sandwich laminate skins. For solid cores, the sandwich is designed so that the normal stresses are taken up by the outer and inner skins of the laminate, while the shear stresses are taken over by the cores.

For soft core sandwich panels, the core does not participate in the shear stresses, and most stresses propagate through the outer and inner skins of the laminate.

\subsection{Creep}

Structures may experience creep if exposed to high level of stress that is still below the yield strength of material over a long period of time. Stress strain curve in such materials oscillate between the elastic region and the viscoelastic region. When it comes to creep in composite materials, factors such as load, temperature, humidity and other external influences have a profound effect. The creep of the composite material has been found to be mostly influenced by matrices, while fibres do not have an influence on the creep mechanism but do alter the creep magnitude and rate [59].

\section{Conclusion}

Due to the variety of case studies, only the most common examples that may appear in practice are presented. Observing those common cases, it is worth of noting that the damaged composite material does not have to experience complete fracture and not all damage is equally hazardous to the material. When not repaired, damage caused by material fatigue, collisions, delamination and separation can ultimately lead to the fracture of the material and ultimately to the failure of the structure itself. The causes 
of such damage are usually external loads, which, due to certain conditions, exceed the permissible stresses. Other damages affect structure over long period of time and, by their mechanisms, weaken the material, but may not necessarily be critical in the short term for the stability of the structure itself. For example, such damage of the gelcoat caused by UV rays, which can usually be repaired with protective coatings without having to repair the whole laminate. The other listed damage may cause severe failure if not treated and requires more invasive techniques and reparation of the layers of the structure.

The area covered by this work is extremely large, and this work only addressed the problems in the field of damage and fracture of composite materials. Comparing the literature on composites with the literature covering the mechanics of fracture of metals and homogeneous materials, it was noticed that there is a lack of systematic review work that would cover the damage and fracture of composite materials and structures relevant to shipbuilding. As such, this paper serves to provide an overview of the mechanisms and mechanics of fracture of a composite, present the current state of technology, technical knowledge and accompanied shipbuilding rules. In authors opinion, it lists and embeds the topic relevant to shipbuilding and clarifies authors area of interest. Deeper investigation of the problems of fracture of composite materials would require more in-depth review of particular field and significant resources.

\section{Acknowledgements}

This research was carried out within the project uniri-technic-18-159 (Development of Methodology for Ship Design and Production towards Industry 4.0. Concept) funded by the University of Rijeka support research program.

\section{References}

1. GREENE, E.: "Marine Composites “, Annapolis: Eric Greene Associates Inc., 1999.

2. BARBERO, E.J.: "Introduction to composite materials design, Second edition ", Boca Raton: Taylor and Francis Group Ltd., 2011.

3. HAHN, H.T., KIM, R.Y.: "Fatigue Behaviour of Composite Laminate", Journal of Composite Materials, 10(2):156-180, 1976.

4. SPEARING, S.M., BEAUMONT, P.W.R.: "Fatigue damage mechanics of composite materials .1. Experimental measurement of damage and post fatigue properties", Composite Science and Technology, 44(2):159-168, 1992.

5. GAMSTEDT, E.K., TALREJA, R.: "Fatigue damage mechanism in unidirectional carbon-fibrereinforced plastics", Journal of Material Science, 34(11):2535-2546, 1999.

6. GAMSTEDT, E.K., OSTLUND, S.: "Fatigue propagation of fibre-bridged cracks in unidirectional polymer-matrix composites", Applied Composite Materials, 8(6):385-410, 2001.

7. SUWARTA, P., FOTOUHI, M., CZEL, G., LONGANA, M., WISNOM, M.R.: "Fatigue behaviour of pseudo-ductile unidirectional thin-ply carbon/epoxy-glass/epoxy hybrid composites", Composite Structures, 224, 2019.

8. MANUJESH, B.J., RAO, V.: "Fatigue Behaviour and Failure Mechanism of PU Foam Core E-glass Reinforced Vinyl Ester Sandwich Composites", International Journal of Materials Engineering, 3(4):66-81, 2013. 
9. BELYTSCHKO, T, BLACK, T.: "Elastic crack growth in finite elements with minimal remeshing”, International Journal for Numerical Methods in Engineering, 45(5):601-620, 1999.

10. DAI, G.M., MISHNAEVSKY, L.: "Fatigue of hybrid glass/carbon composites: 3D computational studies”, Composites Science and Technology, 94:71-79, 2014.

11. LUO, G.M., LIN, Y.H.: "Study on Structural Adhesive Applied to the Bulkhead Joints Subjected to Non-Contact Underwater Explosion”, Journal of Marine Science and Technology, 26(3):421430, 2018.

12. JACKSON, W.C., POE, C.C.: "The Use of Impact Force as a Scale Parameter for the Impact Response of Composite Laminates ", Journal of Composites Technology \& Research, 15(4):282289, 1993.

13. FORT, C.: “Inspecting Old Sailboats”, Boat U.S., https://www.boatus.com/seaworthy/ magazine/2013/july/inspecting-older-sailboats.asp, 2013.

14. KARAKUZU, R., ERBIL, E., AKTAS, M.: "Impact characterization of glass/epoxy composite plates: An experimental and numerical study”, Composites Part B-Engineering, 41(5):388-395, 2010.

15. KUMAR, K., SURENDAN, S.: “Design and analysis of composite panel for impact loads in marine environment”, Ships and Offshore Structures, 8(5):597-606, 2013.

16. TSAI, S.W., HAHN, H.T.: “Introduction to composite materials", Lancaster: Technomic Publishing Company, Inc., 1980.

17. JONES, R.M.: “Mechanics of composite materials - Second edition”, Philadelphia: Taylor \& Francis, 1999.

18. PIPES, R.B., PAGANO, N.J.: “Interlaminar Stress un Composite Laminates Under Uniform Axial Extension”, Journal of Composite Materials, 4:538-, 1970.

19. PIPES, R.B., DANIELS, I.M.: "Moiré Analysis of the Interlaminar Shear Edge Effect in Laminated Composites”, Journal of Composite Materials, 5(2):255-259, 1971.

20. NYMAN, T., FRIBERG, M.: “Interlaminar stress in composite notched and unnotched laminates", Journal of Reinforced Plastics and Composites, 19(1):34-57, 2000.

21. WANG, A.S.D, CROSSMAN, F.W.: "Some New Results on Edge Effect in Symmetric Composite Laminates”, Journal of Composite Materials, 11(JAN):92-106, 1977.

22. RAJU, I.S., CREWS, J.H.: "Interlaminar Stress Singularities at a Straight Free Edge in Composite Laminates", Computers \& Structures, 14(1-2):21-28, 1981.

23. MADHUKAR, M.S., DRZAL, L.T.: "Fibre-matrix Adhesion and its Effects on Composite Mechanical properties .4. Mode I and Mode II Fracture Toughness of Graphite Epoxy Composites”, Journal of Composite Materials, 26(7):936-968, 1992.

24. KASSAPOGLOU, C., LAGACE, P.A.: "An Efficient Method for the Calculation of Interlaminar Stresses in Composite Materials”, Journal of Applied Mechanics-Transactions of the ASME, 53(4):744-750, 1986.

25. KRESS, G., WINKLER, M.: “Corrugated laminate analysis: A generalized plane-strain problem”, Composite Structures, 93(5):1493-1504, 2011.

26. LU, X., RIDHA, M., CHEN, B.Y., TAN, W.B.C., TAY, T.E.: “On cohesive element parameters and delamination modelling”, Engineering Fracture Mechanics, 206:278-296, 2019.

27. CASTAING, P., LEMOINE, L.: "Effects of water-absorption and osmotic degradation on longterm behaviour of glass-fibre-reinforced polyester”, Polymer Composites, 16(5):349-356, 1995.

28. COSTA, M.L., REZENDE, M.C., DE ALMEIDA, S.F.M.: "Strength of Hygrothermally Conditioned Polymer Composites with Voids”, Journal of Composite Materials, 39(21):19431961, 2005.

29. AKAY, M., KONG AH MUN, S., STANLEY, A.: "Influence of Moisture on the Thermal and Mechanical Properties of Autoclaved and Oven-cured Kevlar-49/epoxy Laminates”, Composites Science and Technology, 57:565-571, 1997.

30. KIM, S.S., LEE, H.G., LEE, D.G.: "The tribological behaviour of polymer coated carbon composites under dry and water lubricating conditions”, 77(3):364-327, 2007.

31. POMAZI, A., TOLDY, A.: “Multifunctional Gelcoats for Fibre Reinforced Composites”, 9(3), Article No. 173, 2019.

32. LANDOWSKI, M., BUDZIK, M. IMIELINSKA, K.: “Water absorption and blistering of glass fibre-reinforced polymer marine laminates with nanoparticle-modified coatings", Journal of Composite Materials, 48(23):2805-2813, 2014. 
33. http://www.hotvac.com

34. ZUHAZRI, M.Y., AMIRHAFIZAN, M.H., NILSON, G.C.H., SIHOMBING, H., KAMARUL, A.M., NIRMAL, U.: "Effects of gelcoat thickness on mechanical properties of woven glass/ polyester laminated composites", 12(1):3370-3386, 2018.

35. SCHOLZ, S., KROLL, L., SCHETTLER, F.: "Nanoparticle reinforced epoxy gelcoats for fibreplastic composites under multiple load", Progress in Organic Coatings, 77(7):1129-1136, 2014.

36. RUSSO, A., ZUCCARELLO, B.: "Experimental and numerical evaluation of the mechanical behaviour of GFRP sandwich panels", Composite Structures, 81(4):575-586, 2007.

37. MITRA, N.: "A methodology for improving shear performance of marine grade sandwich composites: Sandwich composite panel with shear key", Composite Structures, 92(5):1065-1072, 2010.

38. MITRA, N., RAJA, B.R.: "Improving delamination resistance capability of sandwich composite column with initial face/core debond", Composites: Part B, 43:1604-1612, 2012.

39. HUSSAIN, M., ABBAS, N., ZAHRA, N., SAJJAD, U., AWAN, M.B.: "Investigating the performance of GFRP/wood-based honeycomb sandwich panels for sustainable prefab building construction", SN Applied Science, 1(8), Article No. UNSP 875, 2019.

40. CAPANESCU, C., CINCU, C.: "Evaluation of UV inhibitors in polyester gelcoats", Advances in Polymer Technology, 22(4):365-372, 2003.

41. AFSHAR, A.: "Synergistic effects of marine environments and flexural fatigue on carbon fibrevinyl ester composites protected by gelcoat", Journal of Composite Materials, 51(26):3711-3717, 2017.

42. WU, E.M.: "Fracture Mechanics of Fibre-Reinforced Composites", Proceedings of ARPA/AFML Review of Progress in Quantitative NDA, 5:7-, 1979.

43. HUTCHINSON, J.W., SUO, Z.: "Mixed-mode Cracking in Layered Materials", Advances in Applied Mechanics, 29:63-191, 1992.

44. WADDOUPS, M.E., EISENMANN, J.R., KAMINSKI, B.E.: "Macroscopic, Fracture Mechanics of Advanced Composite Materials", Journal of Composite Materials, 5:446-454, 1971.

45. BOONE, T.J., WAWRZYNEK, P.A., INGRAFFEA, A.R.: "Finite Element Modelling of Fracture Propagation in Orthotropic Materials", Engineering Fracture Mechanics, 26(2):185-201, 1987.

46. ABDULLAH, N.A., CURIEL-SOSA, J.L.,TAYLOR, Z.A., TAFAZZOLIMOGHADDAM, B., VINCENTE, J.L.M. ZHANG, C.: "Transversal crack and delamination of laminates using XFEM", Composite Structures, 173:78-85, 2017.

47. ROSEN, B.: "Tensile failure of fibrous composites", AIAA Journal, 2(11):1985-1991, 1964.

48. BARBERO, E.J., DAMIANI, T.M.: "Phenomenological prediction of tensile strength of E-glass composites from available aging and stress corrosion data", Journal of Reinforced Plastics and Composites, 22(4):373-394, 2003.

49. KUMAR, M.S., RAGHAVENDRA, K., VENKATASWAMY, M.A.,ROMACHANDRA, H.V.: "Fractographic Analysis of Tensile Failures of Aerospace Grade Composites", Materials Research, 15(6):990-997, 2012.

50. KUHN, P., CATALANOTTI, G., XAVIER, J., PLOECKL, M., KOERBER, H.: “Determination of the crack resistance curve for interlaminar fibre tensile failure mode in polymer composites under high rate loading”, Composite Structures, 204:276-287, 2018.

51. WANG, F., DING, J., CHEN, Z.: "Statistical Analysis of the Progressive Failure Behaviour for Fibre-Reinforced Polymer Composites under Tensile Loading”, Polymers, 6(1):145-159, 2014.

52. OKABE, T., NISHIKAWA, M., TOYOSHIMA, H.: "A periodic unit-cell simulation of fibre arrangement dependence on the transverse tensile failure in unidirectional carbon fibre reinforced composites", International Journal of Solids and Structures, 48:2948-2959, 2011.

53. BUDINSKY, B., FLECK, N.A.: "Compressive failure of fibre composites", Journal of the Mechanics and Physics of solids, 41(1):183-211, 1993.

54. LARSON, L., ELIASSON, R.E.: "Principles of yacht design, second edition”, London: Adlard Coles Nautical, 2000.

55. CVITKOVICH, M.K, JACKSON, W.: "Compressive Failure Mechanisms in Composite Sandwich Structures”, Journal of American Helicopter Society, 44(4):260-268, 1999.

56. JAPINS, G., KALNINS, K., OZOLINIS, O., SKUKIS, E.: “Compressive failure of quasi-static indented CFTP/aluminium honeycomb sandwich panels", International Conference Baltic Polymer Symposium 2018, 500, Art. No. UNSP012007, 2019. 
57. REDDY, J.N., PANDEY, A.K.: “A First-ply Failure Analysis of Composite Laminate”, Computers \& Science, 52(3):371-393, 1987.

58. ROMANOWICZ, M.: "Determination of the first ply failure load for a cross ply laminate subjected to uniaxial tension through computational micromechanics", International Journal of Solids and Structures, 51(13):2549-2556, 2014.

59. RAGHAVAN, J., MESHII, M.: "Creep of Polymer Composites", Composites Science and Technology, 57(12):1673-1688, 1997. 
